\title{
A percepção das pessoas com deficiência sobre o trabalho e a Lei de Cotas: uma revisão da literatura
}

| ${ }^{1}$ Pollyanna Salles Rodrigues, ${ }^{2}$ Éverton Luís Pereira |

Resumo: A inclusão de pessoas com deficiência no mercado de trabalho foi possível mediante legislaçóes de reserva de vagas, embora ainda seja insuficiente oferecer emprego sem disponibilizar condiçóes de acessibilidade. É relevante investigar as possibilidades e os desafios da inserção da pessoa com deficiência no trabalho, mas poucos estudos partem da sua percepção. Este estudo tem como objetivo compreender como os periódicos brasileiros da Saúde Coletiva de Qualis CAPES acima de B2 estáo abordando a percepçáo das pessoas com deficiência e a influência da Lei de Cotas sobre a inclusão no trabalho. Trata-se de um estudo bibliográfico, do tipo revisão de literatura. Percebe-se que a intersecção entre os estudos sobre deficiência e os estudos sobre o trabalho adentra a saúde coletiva como um tema emergente. A partir da leitura e análise dos artigos, foram criadas quatro categorias: deficiência como desvantagem e restrição de participação; cotas para pessoas com deficiência; percepção da pessoa com deficiência sobre o trabalho e medidas de inclusão social no trabalho. Ainda há muito a se avançar de modo que a extinção de barreiras não esteja somente pautada na organização, na legislação, na educação, mas essencialmente no campo da ideologia, da política e da sociedade.

> Palavras-chave: pessoas com deficiência; percepção social; trabalho.

\author{
' Departamento de Saúde \\ Coletiva, Universidade de Brasília. \\ Brasília-DF, Brasil (pollysallesr@ \\ gmail.com). \\ ORCID: 0000-0003-1775-6819 \\ ${ }^{2}$ Departamento de Saúde \\ Coletiva, Universidade de Brasília. \\ Brasília-DF, Brasil (everton. \\ epereira@gmail.com). \\ ORCID: 0000-0002-7771-1594
}

Recebido em: 30/10/2019 Aprovado em: 12/01/2020 Revisado em: 22/03/2021 


\section{Introdução}

Conferiu-se à pessoa com deficiência, historicamente, a ideia de incapacidade e a exclusão da participação social, por não entenderem a deficiência como expressão da diversidade humana, mas por julgarem que todo corpo fora dos padróes considerados normais não serviria à sociedade, sobretudo no século XVIII, com o surgimento e avanço das sociedades capitalistas industriais (VIANNA, 2018). No mesmo período, o conhecimento médico começou a avançar e buscar na reabilitação, medicalização e institucionalização medidas para alcançar a cura para a deficiência. É nesse contexto que surge o modelo biomédico, reconhecendo na lesão e na limitação corporal a justificativa para a desvantagem e desigualdade social (BAMPI; GUILHEM; ALVES, 2010).

Em oposição ao modelo biomédico, surgiu entre os anos de 1960 e 1970, o modelo social da deficiência em decorrência de movimentos sociais pela luta dos direitos humanos e respeito à diversidade. Esse modelo passou a entender que a deficiência não é uma questão individual, mas um assunto social (VIANNA, 2018). Isto é, a desvantagem experimentada pelo indivíduo não se encontra no corpo com limitaçóes e sim na sociedade pouco ajustada para acolher a diversidade (OLIVER, 1990).

Os modelos biomédico e social da deficiência são matrizes teóricas e políticas que, paulatinamente, foram sendo incorporados aos marcos legislativos e nas políticas públicas, como foi o caso da Lei Brasileira de Inclusão da Pessoa com Deficiência, que tomou como base a Convenção sobre os Direitos das Pessoas com Deficiência. Dessa forma, a deficiência passou a ser definida pela perspectiva biopsicossocial, a qual leva em consideração os impedimentos nas funçôes e nas estruturas do corpo; os fatores socioambientais, psicológicos, pessoais e a limitação no desempenho de atividades (BRASIL, 2009; 2015). Portanto, a deficiência não é expressa somente nas limitações do corpo com lesão, como também nas barreiras atitudinais e nos ambientes que impedem a plena participação das pessoas com deficiências (BRASIL, 2009).

O intuito da Convenção é promover, salvaguardar e garantir o exercício de todos os direitos das pessoas com deficiência, dentre eles, o direito ao trabalho em igualdade de oportunidades com os demais indivíduos (BRASIL, 2009). Sobretudo para as pessoas com deficiência, o trabalho oportuniza sair da situação de isolamento social, criar independência da família, além de desenvolver autonomia financeira e de vida (LIMA, 2013). 
Segundo a Organização Internacional do Trabalho (2015), as pessoas com deficiência representam aproximadamente $15 \%$ da população mundial, isto é, um bilhão de pessoas, das quais $80 \%$ estão em idade propícia para o trabalho. Entretanto, o trabalho ainda é um direito frequentemente negado a essas pessoas, que enfrentam grandes barreiras nos ambientes, na informação, na comunicação e nos serviços. Desta forma, experimentam altos índices de desemprego, ausência de atividade econômica, além de maior desproteção social quando comparadas com pessoas sem deficiência, fatores que contribuem para a pobreza extrema.

As cotas para pessoas com deficiência surgiram logo após a I Guerra Mundial com o intuito de garantir uma parcela de trabalho para os veteranos que adquiriram uma deficiência em consequência da guerra e posteriormente, foi expandida para abranger também os acidentados em trabalho. Até o fim da II Guerra Mundial, nova expansão foi realizada de forma a adotar um sistema de cotas mais amplo, incluindo outros tipos de deficiência (METTS, 2000). Com o passar dos anos, sérios problemas começaram a surgir por consequência dessa ampliação, visto que a procura por esse tipo de emprego aumentou significativamente e as empresas passaram a náo ter condiçôes de abarcar todos os tipos de deficiência, além de perceberem que as penalidades não eram aplicadas de forma rigorosa, passando a ignorá-las (METTS, 2000).

No Brasil, a inclusão de pessoas com deficiência no mercado de trabalho, mediante reserva de vagas, foi possível a partir da promulgação da Lei no 8.213 de 1991, conhecida como Lei de Cotas, cujo artigo 93 estabelece que as empresas com cem ou mais empregados ficam obrigadas a preencher de $2 \%$ a $5 \%$ dos seus cargos com beneficiários reabilitados ou pessoas com deficiência habilitadas (BRASIL, 1991). No que diz respeito ao serviço público federal, está estabelecida pela Lei $n^{\circ}$ 8.112 de 1990 , a reserva de vagas com um percentual mínimo de 5\% e o máximo de 20\% para as pessoas com deficiência (BRASIL, 1990).

Seguindo o movimento mundial, o Brasil, a partir da implementação de uma política de inclusão para pessoas com deficiência no trabalho, tem obtido consideráveis resultados, não no que diz respeito ao número de pessoas empregadas no trabalho formal, mas em relaçáo ao debate sobre o direito ao trabalho dessa população (VASCONCELOS, 2010). Ainda que se tenha avançado nos recursos legislativos que resguardam e promovem a empregabilidade das pessoas com deficiência, a quantidade de pessoas com deficiência contratadas ainda é muito 
baixa (ZANITELLI, 2013; COELHO; SAMPAIO; MANCINI, 2014). Ademais, é insuficiente oferecer a vaga de emprego sem disponibilizar de condiçóes de acessibilidade e adaptação, de forma a romper com o preconceito, discriminação e com as barreiras físicas, atitudinais e comunicacionais que são entraves à inclusão (NEVES-SILVA; PRAIS; SILVEIRA, 2015).

Há diversos estudos que levam em conta as pessoas com deficiência e o mundo do trabalho. Sem dúvidas, é de extrema relevância investigar as possibilidades e os desafios da inserção das pessoas com deficiência no mercado de trabalho. Há, porém poucos estudos que partem da percepção da pessoa com deficiência sobre o processo de inclusão social no trabalho. É importante visibilizar essas experiências, visto que tal escuta possibilita a identificação de suas demandas de forma que amplia a discussão sobre o tema. Além disso, essa perspectiva contribui na construção da produção científica e no aprimoramento e tomadas de decisão em políticas públicas inclusivas.

Portanto, considerando a influência do trabalho para o desenvolvimento da identidade das pessoas com deficiência, a influência da Lei de Cotas como política afirmativa para a inserção no mercado de trabalho, as barreiras que são entraves no processo de inclusão social, bem como as mudanças conceituais que a deficiência vem passando, este estudo tem como objetivo compreender como os periódicos brasileiros da Saúde Coletiva classificados no Qualis CAPES acima de B2 estão abordando a temática pessoa com deficiência e trabalho, tendo como foco a análise dos artigos que discorrem sobre a percepção das pessoas com deficiência sobre a inclusão no trabalho, bem como a identificação dos artigos que tratam de cotas para pessoas com deficiência no mercado de trabalho.

\section{Metodologia}

Trata-se de um estudo bibliográfico, do tipo revisão de literatura, que aborda a temática da percepção das pessoas com deficiência sobre o trabalho, utilizando artigos científicos como fonte de análise. Para identificar artigos sobre o assunto realizou-se, durante o mês de outubro de 2018, a consulta nas bases de dados SciELO e LILACS, rastreando artigos publicados em periódicos brasileiros da Saúde Coletiva do triênio 2013-2016 de Qualis A1, A2, B1 e B2. Para contemplar o maior número de estudos, o recorte temporal utilizado na pesquisa foram artigos publicados entre os anos de 2007 a 2018, nos idiomas português e inglês, cujos textos pudessem ser acessados na íntegra. 
As palavras-chave utilizadas na busca foram escritas em português. Na base de dados da SciELo, foram utilizados: deficiência e trabalho, pessoa com deficiência e trabalho, deficiência e inclusão social, pessoa com deficiência e inclusão social, pessoa com deficiência e condição de trabalho, pessoa com deficiência e mercado de trabalho, trabalho e inclusão social. Na base de dados da LILACS, foram utilizos: deficiência or pessoa com deficiência and trabalho, deficiência or pessoa com deficiência and mercado de trabalho, pessoa com deficiência or deficiência and inclusão social, trabalho or mercado de trabalho and inclusão, trabalho or mercado de trabalho and pessoa com deficiência.

Os critérios de inclusão foram: artigos que tratassem da percepção das pessoas com deficiência sobre o trabalho e/ou contemplassem a temática cotas para pessoas com deficiência. Os critérios de exclusão foram: artigos centrados na perspectiva biomédica da deficiência, artigos de pesquisas quantitativas, artigos que tratavam sobre a pessoa com deficiência fora do contexto/âmbito do trabalho. A ideia de inclusão desse perfil de artigos foi no sentido de visibilizar a produção científica pautada na perspectiva e nas experiências das pessoas com deficiência, tal como proposto por Oliver (1992).

A busca retornou 138 artigos na base de dados da Scielo e 137 da Lilacs. Foram descartados os artigos que apareceram mais de uma vez na mesma base indexadora ou que se repetiram em ambas as bases. A primeira seleção dos artigos foi baseada na avaliação dos títulos, de forma que se adequassem aos objetivos gerais da pesquisa, obtendo-se assim 65 artigos.

Para extração dos dados dos artigos, foi elaborada uma tabela contendo as seguintes informações: título, resumo, autores, descritores, ano de publicação, nome do periódico da Saúde Coletiva e classificação Qualis do periódico. Em seguida, foi realizada nova triagem com base na leitura dos resumos, de forma que os artigos selecionados se adequassem aos objetivos específicos, respeitando os critérios de inclusão e exclusão. Desta forma, o corpus de análise foi reduzido a 19 artigos, os quais foram lidos na íntegra utilizando os seguintes passos: leitura exploratória; leitura seletiva dos tópicos mais relevantes e que correspondiam aos objetivos do estudo; leitura analítica, posteriormente realização de leitura interpretativa e análise dos textos para a redação.

Em seguida a estas etapas, estabeleceu-se um corpus de conteúdo agrupando os temas mais abordados em quatro categorias: deficiência como desvantagem e 
restriçãoo de participação, cotas para pessoas com deficiência, percepção da pessoa com deficiência sobre o trabalho e medidas de inclusão social.

\section{Resultados e Discussão}

\section{Caracterizaçáo da produção}

Da primeira seleção de artigos baseada na avaliação dos títulos que se adequavam aos objetivos gerais da pesquisa, foram obtidos 65 artigos. Destes, 19 foram selecionados para análise deste estudo, ou seja, 70,76\% $(n=46)$ dos artigos pré-selecionados não foram analisados visto que estavam centrados na perspectiva puramente biomédica da deficiência, e eram artigos de pesquisas quantitativas, isto é, não abordavam a percepção das pessoas com deficiência sobre o trabalho. Tal achado reflete a forma como a produção sobre deficiência na Saúde Coletiva está sendo construída e expressa nas revistas.

Com relaçáo ao ano de publicação dos artigos que compóem a amostra final, conforme apresentado na tabela 1 , nota-se que a publicação foi bem distribuída no período em questão, excetuando o ano de 2007, no qual nenhum artigo foi selecionado. Por outro lado, o número de produçôes foi elevado no ano de 2015, evidenciando um interesse recente que pode estar relacionado ao possível avanço no processo de inclusão social e cidadania da pessoa com deficiência. Esse avanço pode ser fruto da promulgação, no ano de 2009, da Convenção Internacional sobre os Direitos das Pessoas com Deficiência, o qual preconiza a promoção, proteção, respeito da dignidade, o exercício pleno dos direitos fundamentais e a equiparação de oportunidades às pessoas com deficiência (BRASIL, 2009).

\section{Tabela 1. Distribuiçấo dos artigos conforme o ano de publicação}

\begin{tabular}{cc}
\hline Ano de publicação & n \\
\hline 2007 & 0 \\
2008 & 1 \\
2009 & 1 \\
2010 & 2 \\
2011 & 1
\end{tabular}

continua... 


\begin{tabular}{cc}
\hline Ano de publicação & n \\
\hline 2012 & 2 \\
2013 & 3 \\
2014 & 1 \\
2015 & 5 \\
2016 & 1 \\
2017 & 1 \\
2018 & 1 \\
\hline Total & 19 \\
\hline
\end{tabular}

Fonte: dados da pesquisa.

No que diz respeito aos autores dos artigos, observou-se a presença da multidisciplinaridade de formações, como Administração, Psicologia, Enfermagem, Antropologia, Saúde Pública, Saúde Coletiva, Ciências Sociais, Serviço Social, Direito, Geografia do Trabalho, Terapia Ocupacional, Educação e Educação Especial. Somente duas autoras escreveram mais de um artigo, a primeira atuou como coautora em dois artigos e a segunda como coautora em três artigos, ambas na área da Administração.

Em relação ao campo disciplinar de estudo das revistas nos quais foram selecionados os artigos da amostra final, sete se referem à área de conhecimento da Psicologia; quatro da Administração; três da Saúde Coletiva; dois da Enfermagem; dois da Segurança e Saúde no Trabalho; e um da Antropologia. Para definição das áreas disciplinares, foi utilizada como base a descrição contida no portal específico de cada revista. Esse achado evidencia a Saúde Coletiva como campo multifacetado formado pela agregação de conhecimentos e práxis, contribuindo para o progresso da interdisciplinaridade e multidisciplinaridade com a qual a Saúde Coletiva deve estar fundamentada.

Quanto ao Qualis dos artigos da amostra final, não foi identificado artigos de Qualis A1 e A2, sendo selecionado sete artigos de Qualis B1 e 12 de Qualis B2. Tais fatos corroboram os achados verificados em um estudo sobre a avaliaçáo da produçáo intelectual na Saúde Coletiva sobre a análise do perfil dos periódicos do Qualis da Saúde Coletiva, o qual constatou que os periódicos de estratos superiores (A1, A2 e B1) são majoritariamente da área biomédica e, quanto menor a Qualis, maior 
os periódicos no campo das Ciências Sociais e Humanas (COSTA, 2012). Diante do exposto, tendo em vista que os periódicos da Saúde Coletiva estáo inseridos no âmbito das Ciências da Saúde, é notório o predomínio da hegemonia biomédica nas publicaçóes científicas do campo, e por isso os que estão em estratos superiores são, em sua maioria, direcionados para esse olhar.

Ainda é um desafio romper com a hegemonia biomédica e trazer para o campo da Saúde Coletiva o diálogo com outros campos de conhecimento, sobretudo das disciplinas que compóem o subcampo das Ciências Sociais, atualmente designado Ciências Sociais e Humanas em Saúde. Diferentemente das disciplinas clássicas da área da Biologia, que possuem um olhar tão somente técnico sobre a vida, tanto em grau metodológico quanto epistemológico, compete aos conceitos, objetos e metodologias das Ciências Sociais, compreender e interpretar os acontecimentos socioculturais ligados à saúde e abranger em sua totalidade os eventos da vida humana sob a perspectiva coletiva e comunitária (LUZ, 2011). Por este motivo, o perfil desejado para selecionar os artigos do presente estudo, construído por meio dos critérios de inclusão e exclusão, está em diálogo com as metodologias qualitativas e com a área da Saúde Coletiva, Ciências Sociais e Humanas em Saúde.

Tendo em vista que consideram a participaçâo da coletividade e dos sujeitos envolvidas em determinada problemática, as Ciências Sociais e Humanas têm tido a expressiva função de fomentar conceitualmente políticas inovadoras em saúde, como também políticas alternativas (LUZ, 2011). Essa proposta das Ciências Sociais e Humanas em Saúde pode contemplar um novo olhar sobre a deficiência, como preconizado pelos pesquisadores com deficiência dos disability studies (OLIVER, 1992; BARTON, 2005).

É importante trazer para oâmbito social e político, questôes e temas historicamente considerados restritos à Medicina, como é o caso dos estudos sobre a deficiência. Partir da percepção e dar voz aos sujeitos, para além da manifestação da medicina, com o intuito de tentar compreender a deficiência, é fundamental para delimitar os problemas e delinear as soluçôes, bem como produzir mudanças positivas na sociedade, na vida das pessoas com deficiência e na própria forma de produzir ciência (LUZ, 2011; MARTINS et al., 2012). Essa demanda é crucial para refletirmos sobre o papel das Ciências Sociais e os temas emergentes na Saúde Coletiva e na disputa de saberes do campo. Entretanto, a importância da inserção de pesquisas qualitativas e que abordam a problemática sob a perspectiva das pessoas envolvidas - neste caso, as 
pessoas com deficiência - ainda não são valorizadas nos periódicos científicos, como constatamos com relação à qualificação realizada pelo Qualis CAPES.

Com relação ao conteúdo central dos artigos, 11 artigos tratavam sobre percepção da pessoa com deficiência sobre o trabalho; quatro sobre cotas para pessoas com deficiência; e quatro simultaneamente a respeito da percepção sobre o trabalho e cotas para pessoas com deficiência.

\section{Categorização temática}

A partir da leitura e análise dos artigos foi possível criar quatro categorias por meio da correlação de áreas temáticas. Essas categorias possuem o intuito de compilar a percepção da pessoa com deficiência a respeito do trabalho e da Lei de Cotas, de modo a compreender como enxergam a si mesmas, o contexto social de trabalho que estão inseridas, o papel das legislaçóes e por fim, propor ações complementares que possibilitem a acessibilidade e a inclusão social no trabalho. São elas: deficiência como desvantagem e restrição de participação; cotas para pessoas com deficiência; percepção da pessoa com deficiência sobre o trabalho e medidas de inclusão social no trabalho.

Todas as categorias foram discutidas à luz dos artigos selecionados para o presente estudo.

\section{Deficiência como desvantagem e restrição de participaçáo}

Ao realizar a análise dos 19 artigos que compóem a amostra final da pesquisa, verificou-se que $47,4 \%(n=9)$ dos estudos traziam relatos das pessoas com deficiência que participaram dos estudos que compreendiam a deficiência não como expressão da diversidade humana, mas sim como desvantagem, restrição corporal e/ou restrição de participação.

É comum a sociedade e, em muitos casos, a própria família, reforçar o estigma de que a pessoa com deficiência é incapaz de realizar atividades diárias ou de trabalho de forma independente e autônoma em razão da limitação física expressa em seu corpo. Desde muito cedo, precisam aprender a lidar com o tratamento diferenciado dos demais (MOREIRA; CAPPELLE; CARVALHO-FREITAS, 2015) e com o sentimento de não pertencimento e exclusão social (LIMA, 2013).

Atitudes preconceituosas e estereótipos são impeditivos no processo de inclusão, visto que são barreiras que reduzem as oportunidades e a visualização da capacidade individual da pessoa com deficiência (LIMA, 2013). As maiores desvantagens que as 
pessoas com deficiência apresentam em relação às demais pessoas não são motivadas por suas limitaçóes corporais, mas pela discriminação e falta de reconhecimento quanto às suas potencialidades (BITTENCOURT; FONSECA, 2011).

O trabalho é um dos principais meios de convívio social que oportuniza a inserção e o resgate do sentimento de pertencente à sociedade (LIMA, 2013). Porém, nesse contexto, tem-se percebido que a deficiência quando evidenciada no corpo com lesão ou na funcionalidade, ainda é relacionada a significados negativos, interpretada como desvantagem e incapacidade (HAMMES; NUERNBERG, 2015). Tal fator tem contribuído para reforçar a identidade do indivíduo de maneira negativa, refletindo em seu comportamento o estado depressivo, o sentimento de rejeição, falta de reconhecimento, autopreconceito, tendência a esconder suas lesôes e/ou limitaçóes corporais ou entáo provocando a necessidade de se adaptar e superar suas limitaçooes (LEAL; MATTOS; FONTANA, 2013; COELHO; SAMPAIO; MANCINI, 2014; LOPES; LEITE, 2015).

Estudo (LOPES; LEITE, 2015) realizado com policiais militares com deficiências adquiridas apontou que a aquisição de uma lesão ou limitação física pode interromper ou impossibilitar o exercício de sua atividade profissional, uma vez que tem requisitos preestabelecidos de padrão corporal e social para exercer a profissão. Essa acepção reforçou a visão da deficiência como sinônimo de ineficiência e invalidez. Diante disso, é notório segundo os estudos aqui trabalhados, que sob ponto de vista da pessoa com deficiência, sempre haverá uma desvantagem que limita a exposição de suas capacidades e sua plena participaçáo social, questôes essencialmente estruturadas no campo social e simbólico (VASCONCELOS, 2010).

Também foi constatado (LEÃO; SILVA, 2012) que para alguns trabalhadores com deficiência, a deficiência é vista como entrave ao crescimento profissional e à legítima inclusão ao trabalho. Foi apontado na pesquisa de Coelho, Sampaio e Mancini (2014) que, para que a pessoa com deficiência alcance as mesmas realizaçóes profissionais e níveis de produtividade que as demais pessoas, bem como se destaque por suas qualidades e potencialidades, é necessário maior esforço pessoal, possuir um diferencial e buscar se superar em suas limitaçóes.

Outro ponto a ser ressaltado é a maior dificuldade de contratação e o ingresso de pessoas com deficiência no mercado de trabalho em virtude de diversos fatores mencionados nos estudos, entre eles: estigma gerado pelo preconceito e discriminação, uma vez que impedem a inclusão (FRANCELIN; MOTTI; MORITA, 2010; 
VASCONCELOS, 2010; BITTENCOURT; FONSECA, 2011; LIMA, 2013; LEAL; MATTOS; FONTANA, 2013; ZANITELLI, 2013; COELHO; SAMPAIO; MANCINI, 2014; HAMMES; NUERNBERG, 2015; MOREIRA; CAPPELLE; CARVALHO-FREITAS, 2015; NEVES-SILVA; PRAIS; SILVEIRA, 2015; REIS, 2017); desvantagens na execução de determinadas atividades causadas pela limitação corporal e restrição de habilidades funcionais (VASCONCELOS, 2010; LEAL; MATTOS; FONTANA, 2013; LOPES; LEITE, 2015); exigência de níveis cada vez mais crescentes de escolaridade e qualificação profissional, pois as pessoas com deficiência possuem menores oportunidades de estudo (FRANÇA; PAGLIUCA, 2009; BITTENCOURT; FONSECA, 2011; LEAL; MATTOS; FONTANA, 2013; MACCALI, 2015; MOREIRA; CAPPELLE; CARVALHO-FREITAS, 2015; NEVES-SILVA; PRAIS; SILVEIRA, 2015); despreparo das organizaçóes para receber a pessoa com deficiência em razão da falta de acessibilidade (VASCONCELOS, 2010; HAMMES; NUERNBERG, 2015; NEVES-SILVA; PRAIS; SILVEIRA, 2015); ambientes de trabalho pouco adaptados às características da pessoa com deficiência (FRANÇA; PAGLIUCA, 2009; LEÃO; SILVA, 2012; LIMA, 2013; LEAL; MATTOS; FONTANA, 2013; NEVES-SILVA; PRAIS; SILVEIRA, 2015) e o descumprimento da legislação vigente (BITTENCOURT; FONSECA, 2011).

\section{Percepçáo da pessoa com deficiência sobre o trabalho}

No campo de investigação sobre a importância do trabalho para as pessoas com deficiência, 42,1\% ( $n=8)$ dos artigos levantaram a ideia de que o contexto de trabalho estimula a construção da identidade do indivíduo, por ser um espaço propício para a interação social, além de proporcionar autonomia financeira e pessoal.

As experiências vivenciadas no e por meio do trabalho provocam transformaçóes significativas na pessoa com deficiência à medida que o reconhecimento de seu trabalho gera a sensação de estar sendo útil e deixar de ser invisível para a sociedade (LIMA, 2013). Certamente o significado do trabalho está vinculado ao seu caráter social ao proporcionar o sentimento de igualdade por meio da inserção e integração, bem como oportuniza a ampliação de sua rede social, modificando a situação de isolamento social (LIMA, 2013; COELHO; SAMPAIO; MANCINI, 2014).

Outro ponto bastante discutido sobre o significado do trabalho para as pessoas com deficiência foi a questão da superação dos seus limites e o êxito por ter conseguido um emprego (LEAL; MATTOS; FONTANA, 2013). Inegavelmente, 
o trabalho é tido como eixo central da vida, visto que proporciona independência pessoal, financeira, autonomia de planejar a própria vida, decidir sobre o futuro, exercer o direito de cidadania e romper com o mito que a pessoa com deficiência é incapaz e dependente da família (LIMA, 2013).

Muitas pessoas com deficiência vivenciam a tensão entre escolher o recebimento do Benefício de Prestaçáo Continuada (BPC) e as possíveis vantagens de ingressar no mercado de trabalho. Segundo o artigo 21-A da Lei no 8.742/1993, incluído pela Lei no $12.470 / 2011$, o recebimento do BPC se extingue quando a pessoa com deficiência exercer atividade remunerada. Porém, incluiu também o parágrafo $1^{\circ}$ no artigo 21-A, o qual proporciona a volta do benefício suspenso quando extinta a relação trabalhista (BRASIL, 1993; BRASIL, 2011). No entanto, para as pessoas com deficiência investigadas, apesar de considerarem todas as barreiras e preconceitos que enfrentariam no trabalho, começar a trabalhar foi a opçáo escolhida em virtude das vantagens sociais e pessoais proporcionadas pelo trabalho (HAMMES; NUERNBERG, 2015; NEVES-SILVA; PRAIS; SILVEIRA, 2015). Desta forma, percebe-se a importância dada ao trabalho para a pessoa com deficiência (PEREIRA; DEL PRETTE; DEL PRETTE, 2008).

Vários fatores negativos em relação ao trabalho foram verificados, entre eles o que merece destaque foi a desvalorizaçáo profissional sugerida pelo preconceito de que a pessoa com deficiência é incapaz ou limitada. Ficou demonstrado em 52,6\% $(\mathrm{n}=10)$ dos artigos, segundo os relatos das pessoas com deficiência, que o preconceito por parte dos empregadores leva à contratação desses trabalhadores para ocuparem cargos operacionais. Ademais, as vagas de emprego estáo cada vez mais rigorosas nas exigências curriculares (HAMMES; NUERNBERG, 2015) e quando associadas ao preconceito quanto à capacidade de aprendizagem dessa populaçáo, têm levado os empregadores a direcionarem as pessoas com deficiência a executarem atividades simples e repetitivas (LIMA, 2013; COELHO; SAMPAIO; MANCINI, 2014). Atrelada a este fato, é evidente a desvalorização profissional e o pagamento de baixos salários (PEREIRA; DEL PRETTE; DEL PRETTE, 2008; ZANITELLI, 2013; HAMMES; NUERNBERG, 2015).

Foi manifestado também em $47,4 \%$ (n=9) dos estudos o despreparo das empresas para lidar com a diversidade e a inadequada acessibilidade e adaptação dos ambientes de trabalho para receber os trabalhadores com deficiência. Quando a adaptação é indevida ou sequer realizada, dificulta o processo de inclusão, a expressão da 
autonomia, potencialidade e independência da pessoa com deficiência. O trabalho se torna mais produtivo e executado em igualdade com os demais quando as barreiras de ordem atitudinal, arquitetônica, de informação e comunicação são eliminadas e a acessibilidade é garantida (NEVES-SILVA; PRAIS; SILVEIRA, 2015). Além de tudo, quando o ambiente é adequado às necessidades da pessoa com deficiência, este se sente mais seguro, satisfeito e menos estressado, fatores que refletem na saúde e em outros espaços da vida do indivíduo, como por exemplo, a convivência familiar, a socialização, o descanso etc. (COELHO; SAMPAIO; MANCINI, 2014).

O que se nota é um esforço pessoal muito grande em superar as dificuldades, transpor as condiçôes desfavoráveis e se adaptar ao ambiente devido ao despreparo das empresas para receber e lidar com os trabalhadores com deficiência. No entanto, o correto seria que as organizaçóes e a sociedade se ajustassem para garantir sua plena participação (LEÁO; SILVA, 2012).

\section{Cotas para pessoas com deficiência}

Apesar de a Lei de Cotas para as pessoas com deficiência ter ampliado e oportunizado a entrada desse grupo populacional no mercado de trabalho, foi observado que $42,1 \%(n=8)$ dos artigos trouxeram o argumento que a proposta apenas inseriu a pessoa com deficiência no mercado de trabalho, mas não proporcionou a efetiva inclusão, em virtude da falta de acessibilidade e existência de barreiras, urbanísticas, arquitetônicas, nas comunicaçōes e nas informações e atitudinais.

É inegável que o sistema de cotas impulsionou e trouxe à tona o direito ao trabalho das pessoas com deficiência. Porém, é evidente que a Lei de Cotas se torna insuficiente ou com pequena chance de obter bons resultados quando realizada isoladamente e não atrelada a outras políticas afirmativas que deem condiçôes ao trabalhador com deficiência para ingressar e continuar no mercado de trabalho (VASCONCELOS, 2010).

Notou-se também que existe entre as pessoas com deficiência o receio de que as cotas reforcem o estigma de que elas só são capazes de conseguir um trabalho por causa da obrigatoriedade legal. Dessa forma, os estudos de Vasconcelos (2010) e Zanitelli (2013) argumentam que as oportunidades de trabalho deveriam ser oferecidas independentemente da discriminação advinda dos aspectos físicos e limitaçóes corporais e passasse a ser medida com base nas capacidades e potencialidades do indivíduo. 
Para exemplificar o cenário de preconceito e discriminação, é comum verificar que as organizaçóes contratam pessoas com deficiências consideradas leves, somente para preencher as vagas preconizadas na legislação (VASCONCELOS, 2010; ZANITELLI, 2013; NEVES-SILVA; PRAIS; SILVEIRA, 2015). Além disso, as deficiências menos graves não demandam adaptação no ambiente de trabalho; consequentemente, geram menores custos financeiros às organizaçôes (NEVESSILVA; PRAIS; SILVEIRA, 2015).

\section{Medidas de inclusão social no trabalho}

Sem dúvidas, o desenvolvimento de políticas públicas para as pessoas com deficiência proporciona a transformação social. Discutiu-se e ressaltou-se em $57,9 \%(\mathrm{n}=11)$ dos artigos a necessidade de um refinamento das políticas públicas e organizacionais, a fim de proporcionar a efetiva inclusão no trabalho.

Em suma, os estudos apontam que, apesar de a Lei de Cotas se constituir como política afirmativa na busca pela equidade e redução do preconceito, sozinha não é suficiente para promover a inclusão no trabalho de maneira ampla e eficiente (NEVES-SILVA; PRAIS; SILVEIRA, 2015). É necessário que as organizaçóes também estejam envolvidas nesse processo, praticando políticas internas que alavanquem a diversidade e promovam açôes inclusivas. Uma medida efetiva para acolher os trabalhadores com deficiência é oferecendo programas de treinamento no âmbito da educação profissional com o intuito de reduzir as desigualdades na produtividade em relação aos outros trabalhadores, bem como incluir açôes que melhorem os relacionamentos interpessoais e habilidades sociais. Também é importante disponibilizar monitores para acompanhar durante todo período de aprendizagem e permanência na organização (PEREIRA; DEL PRETTE; DEL PRETTE, 2008; ZANITELLI, 2013; MACCALI, 2015; AYDOS, 2016) e desenvolver atividades de sensibilização aos trabalhadores no geral, com o objetivo de melhorar o convívio.

Surgiu no final na década de 1970, nos Estados Unidos, uma expressão nomeada supported employment, traduzida para o português como emprego apoiado, o qual mostrou que as pessoas com deficiência, muitas vezes consideradas não aptas para o trabalho, poderiam exercer atividades de trabalho se lhes fossem proporcionado o apoio necessário. A principal ideia do emprego apoiado é auxiliar as pessoas com deficiência a conquistar, permanecer no emprego e obter resultados de integração similares aos dos 
outros trabalhadores, por meio do acompanhamento e suporte especializado durante todos os processos de trabalho (COELHO; ORNELAS, 2010; SOUSA, 2000).

Ressaltamos ainda a importância de investir em educação pública inclusiva e em capacitação profissional de qualidade. Porém, apesar de a inclusão de pessoas com deficiência no trabalho estar pautada no âmbito das organizações, da legislação, educação e cultura, é preciso também fomentar mudanças mais profundas como no campo da ideologia, da economia e política. É na sociedade que a eliminação de barreiras deve ter início, por meio de atitudes coletivas que levam à mobilização social e à cobrança para que o Estado cumpra seu papel em busca de uma sociedade mais justa e equânime.

\section{Considerações finais}

Investigar a inclusão de pessoas com deficiência no mundo do trabalho, sobretudo sob o olhar dessa população, é um desafio que requer espaço de abertura para a escuta de suas demandas, de forma a fornecer subsídios para a ampliação da produção científica na área da Saúde Coletiva, bem como avançar no aprimoramento de políticas públicas afirmativas.

Assim como a Convenção sobre os Direitos das Pessoas com Deficiência, que é uma política afirmativa que objetiva garantir oportunidades e tratamento em igualdades de condiçóes com as demais pessoas, a Lei de Cotas também foi criada pensada para diminuir desigualdades historicamente acumuladas, compensar perdas estimuladas pelo preconceito e marginalizaçáo social e oportunizar o direito ao trabalho das pessoas com deficiência. Nesse sentido, a proposta deste estudo foi compreender como os periódicos brasileiros da Saúde Coletiva estão abordando a percepção das pessoas com deficiência e a influência da Lei de Cotas sobre a inclusão no trabalho.

Observou-se que a deficiência é vista como desvantagem que restringe a plena participação social, motivada não pelas limitaçôes corporais, mas principalmente por atitudes preconceituosas e estereótipos que estigmatizam as pessoas com deficiência como incapazes e por isso, reduzem as oportunidades de conseguir um emprego e dificultam a inclusão social.

Os maiores impeditivos do ingresso de pessoas com deficiência no mercado de trabalho são: a discriminação e descrença quanto a suas potencialidades, o despreparo das organizaçóes para receber a pessoa com deficiência em razão da falta de acessibilidade, a baixa escolaridade e a insuficiente qualificação profissional das 
pessoas com deficiência. Nesse sentido, apesar de a Lei de Cotas assegurar o direito ao trabalho e inserir as pessoas com deficiência, sozinha não pode garantir a efetiva inclusão e a permanência no trabalho. Para tal, é fundamental que exista capacitação profissional, preparo social, estrutural, funcional e organizacional no meio do qual a pessoa com deficiência irá fazer parte.

Ainda há muito a se avançar quanto à inclusão de pessoas com deficiência no trabalho de modo que a extinção de barreiras náo esteja somente pautada na organização, na legislação, na educação, mas essencialmente no campo da ideologia, da política e da sociedade. Como bem definido pelo modelo social da deficiência, a causalidade das desvantagens vivenciadas pelas pessoas com deficiência se encontra na estrutura social que está pouco preparada em prever e se adaptar à diversidade. A inclusão social não é um conjunto de ação, mas uma prática, um propósito da sociedade, de consciência coletiva, de respeito às diferenças que fazem a real inclusão existir (HAMMES; NUERNBERG, 2015).

A pesquisa mostrou alguns limites: amostra pequena devido à limitação de rastreamento de periódicos brasileiros da Saúde Coletiva do triênio 2013-2016 e de Qualis acima de B2; ratificou, entretanto, que é baixo o número de publicaçóes sobre a percepção da pessoa com deficiência sobre o trabalho. Portanto, mais estudos sobre o tema são necessários, não apenas no que diz respeito ao mundo do trabalho, mas ao que se refere a políticas sociais inclusivas. Este estudo pode contribuir, assim, para futuras pesquisas na área da Saúde Coletiva com o intuito de ampliar o campo temático. ${ }^{1}$

\section{Referências}

AYDOS, V. Agência e subjetivação na gestão de pessoas com deficiência: a inclusão no mercado de trabalho de um jovem diagnosticado com autismo. Horiz. antropol. Porto Alegre, v. 22, n. 46, p. 329-358, dez. 2016.

BAMPI, L. N. S.; GUILHEM, D.; ALVES, E. D. Modelo social: uma nova abordagem para o tema deficiência. Rev. Latino-Am. Enfermagem. Ribeirão Preto, v. 18, n. 4, p. 816-823, ago. 2010. BARTON, L. Emancipatory research and disabled people: some observations and questions. Educational Review, v. 57, n. 3, ago. 2005.

BITTENCOURT, Z. Z. L. de C.; FONSECA, A. M. R. da. Percepçôes de pessoas com baixa visão sobre seu retorno ao mercado de trabalho. Paideia (Ribeirão Preto), v. 21, n. 49, p. 187195, ago. 2011. 
BRASIL. Lei no 12.470, de 6 de julho de 2011. Altera a Lei no 8.742, de 7 de dezembro de 1993, que dispóe sobre a organização da Assistência Social. Presidência da República. Casa Civil. Brasília, DF, 2011. Disponível em:<http://www.planalto.gov.br/ccivil_03/_ato2011-2014/2011/ lei/l12435.htm>. Acesso em: 11 abr. 2019.

. Lei no 13.146, de 6 de julho de 2015. Institui a Lei Brasileira de Inclusão da Pessoa com Deficiência (Estatuto da Pessoa com Deficiência). Presidência da República. Casa Civil. Brasília, DF, 2015. Disponível em: <http://www.planalto.gov.br/ccivil_03/_ato2015-2018/2015/ lei/l13146.htm>. Acesso em: 11 abr. 2019.

Lei $\mathrm{n}^{\circ}$ 8.112, de 11 de dezembro de 1990. Dispóe sobre o regime jurídico dos servidores públicos civis da União, das autarquias e das fundaçôes públicas federais. Diário Oficial da República Federativa do Brasil. Brasília, DF, 19 abr., 1991. Disponível em: <http:// www.planalto.gov.br/ccivil_03/leis/L8112cons.htm.> Acesso em: 11 abr. 2019.

. Lei no 8.213, de 24 de julho 1991. Dispóe sobre os Planos de Benefícios da Previdência Social e dá outras providências. Presidência da República. Casa Civil. Brasília, DF, 1991. Disponível em: <http://www6.senado.gov.br/legislacao/ListaTextoIntegral.action?id=75662>. Acesso em: 10 abr. 2019.

. Lei no 8.742 , de 7 de dezembro de 1993. Dispóe sobre a organização da assistência social e dá outras providências. Brasília, DF, 1993b. Presidência da República. Casa Civil. Brasília, DF, 1993. Disponível em:<http://www.planalto.gov.br/ccivil_03/leis/l8742.htm>. Acesso em: 11 abr. 2019.

. Presidência da República. Decreto n 6.949 , de 25 de agosto de 2009 - Promulga a Convenção Internacional sobre os Direitos das Pessoas com Deficiência e seu Protocolo facultativo, assinado em Nova York, em 30 de março de 2007. Organizaçáo das Naçóes Unidas - ONU. Disponível em: <http://www.planalto.gov.br/ccivil_03/_Ato2007-2010/2009/ Decreto/D6949.htm>. Acesso em: 17 abr. 2019.

COELHO, C. M.; SAMPAIO, R. F.; MANCINI, M. C. Trabalhadores com deficiência: vivências de prazer e sofrimento. Psicol. Soc., Belo Horizonte, v. 26, n. 1, p. 214-223, abr. 2014.

COELHO, V. P.; ORNELAS, J. Os contributos do emprego apoiado para a integração das pessoas com doença mental. Aná. Psicológica, Lisboa, v. 28, n. 3, p. 465-478, set. 2010.

COSTA, N. do R. A avaliação da produção intelectual e o declínio da interdisciplinaridade na Saúde Coletiva. Physis, Rio de Janeiro, v. 22, n. 2, p. 681-699, jun. 2012.

FRANÇA, I. S. X. de; PAGLIUCA, L. M. F. Inclusão social da pessoa com deficiência: conquistas, desafios e implicações para a enfermagem. Rev. esc. enferm. USP, São Paulo, v. 43, n. 1, p. 178-185, mar. 2009.

FRANCELIN, M. A. S.; MOTTI, T. F. G.; MORITA, I. As implicações sociais da deficiência auditiva adquirida em adultos. Saude soc. São Paulo, v. 19, n. 1, p. 180-192, mar. 2010. 
HAMMES, I. C.; NUERNBERG, A. H. A inclusão de pessoas com deficiência no contexto do trabalho em Florianópolis: relato de experiência no Sistema Nacional de Emprego. Psicol. cienc. prof., Brasília, v. 35, n. 3, p. 768-780, set. 2015.

LEAL, D. R.; MATTOS, G. D. de; FONTANA, R. T. Trabalhador com deficiência física: fragilidades e agravos autorreferidos. Rev. bras. enferm. Brasília, v. 66, n. 1, p. 59-66, fev. 2013.

LEĀO, M. A. B. G.; SILVA, L. S. Vivências de trabalhadores com deficiência: uma análise à luz da Psicodinâmica do Trabalho. Rev. bras. saúde ocup. São Paulo, v. 37, n. 125, p. 159-169, jun. 2012.

LIMA, M. P. de et al. O sentido do trabalho para pessoas com deficiência. RAM, Rev. Adm. Mackenzie, São Paulo, v. 14, n. 2, p. 42-68, abr. 2013.

LOPES, E. M. de C.; LEITE, L. P. L. Deficiência adquirida no trabalho em policiais militares: significados e sentidos. Psicologia \& Sociedade. Sáo Paulo, v. 27, n. 3, p. 668-677, mar. 2015.

MACCALI, N. et al. As práticas de recursos humanos para a gestão da diversidade: a inclusão de deficientes intelectuais em uma federação pública do Brasil. RAM, Rev. Adm. Mackenzie. São Paulo, v. 16, n. 2, p. 157-187, mar./abr. 2015.

MARTINS, B. S. et al. A emancipação dos estudos da deficiência. Revista Crítica de Ciências Sociais, 98, p. 45-64, set. 2012. Disponível em: <https://estudogeral.sib.uc.pt/ bitstream/10316/33402/1/A\%20emancipa\%C3\%A7\%C3 A3o\%20dos\%20estudos\%20da\%20 defici\%C3\%AAncia.pdf>. Acesso em: 2 maio 2019.

METTS, R. L. Disability issues, trends and recommendations for the World Bank. Washington, DC, 2000. Disponível em: <http://documents.worldbank.org/curated/ en/503581468779980124/pdf/multi0page.pdf>. Acesso em: 11 abr. 2019.

MOREIRA, L. B.; CAPPELlE, M. C. A.; CARVALHO-FREITAS, M. N de. A dinâmica identitária de pessoas com deficiência: um estudo no Brasil e nos Estados Unidos. RAM, Rev. Adm. Mackenzie, São Paulo, v. 16, n. 1, p. 40-61, fev. 2015.

NEVES-SILVA, P.; PRAIS, F. G.; SILVEIRA, A. M. Inclusão da pessoa com deficiência no mercado de trabalho em Belo Horizonte, Brasil: cenário e perspectiva. Ciênc. saúde coletiva, Rio de Janeiro, v. 20, n. 8, p. 2549-2558, ago. 2015.

OLIVER, M. Changing the Social Relations of Research Production? Disability \& Society, v. 7, n. 2, p. 101-114, 1992.

OLIVER, M. The Politics of Disablement. London: MacMillan, 1990.

ORGANIZAÇÃO INTERNACIONAL DO TRABALHO. Disability inclusion strategy and action plan 2014-17: a twin-track approach of main streaming and disability-specifications / International Labour Office. Geneva: ILO, 2015. Disponível em: <https://www.ilo.org/ wcmsp5/groups/public/---ed_emp/---ifp_skills/documents/publication/wcms_640908.pdf>. Acesso em: 11 abr. 2019. 
PEREIRA, C. de S.; DEL PRETTE, A.; DEL PRETTE, Z. A. P. Qual o significado do trabalho para as pessoas com e sem deficiência física? Psico-USF, v. 13, n. 1, p. 105-114, jan-jun. 2008.

REIS, R. J. de S. et al. Dignity promoted or violated: how does the deaf person included perceive it? RAM, Rev. Adm. Mackenzie, São Paulo, v. 18, n. 3, p. 178-202, jun. 2017.

SOUSA, A. Emprego apoiado: uma primeira abordagem. Psicologia, Lisboa, v. 14, n. 1, p. $73-$ 82, jan. 2000.

VASCONCELOS, F. D. O trabalhador com deficiência e as práticas de inclusão no mercado de trabalho de Salvador, Bahia. Rev. bras. saúde ocup. São Paulo, v. 35, n. 121, p. 41-52, jun. 2010.

VIANNA, N. G. Ruídos e silêncios: uma análise genealógica sobre a surdez na política de saúde brasileira. Tese (Doutorado)- Faculdade de Ciências Médicas da Universidade Estadual de Campinas, Campinas, 2018.

ZANITELLI, L. M. A lei de cotas para pessoas portadoras de deficiência nas empresas brasileiras: impacto e possíveis alternativas. Ciênc. saúde coletiva, Rio de Janeiro, v. 18, n. 7, p. 2085-2094, jul. 2013.

\section{Nota}

${ }^{1}$ P. S. Rodrigues: concepção e delineamento da pesquisa; consulta nas bases de dados; análise e interpretaçáo de dados; redaçáo e aprovação da versão final do artigo. E. L. Pereira: delineamento da pesquisa; interpretação de dados; redação e aprovação da versão final do artigo. 


\section{Abstract}

\section{The perception of people with disabilities about work and the Law of Quotas: a literature review}

The inclusion of people with disabilities in the labor market was possible through legislation reserving vacancies, however, it is still insufficient to offer employment without providing accessibility conditions. It is relevant to investigate the possibilities and the challenges of the insertion of the disabled person in the work, but few studies depart from their perception. This study aims to understand how the Brazilian journals of Collective Health of Qualis CAPES above B2 are addressing the perception of people with disabilities and the influence of the Law of Quotas on inclusion in work. This is a bibliographical study, like literature review. It is perceived that the intersection between the studies on disability and studies on the work enters Collective Health as an emergent subject. From the reading and analysis of the articles, four categories were created: disability as a disadvantage and restriction of participation; quotas for people with disabilities; the perception of the disabled person about work and social inclusion measures at work. There is still a long way to go so that the elimination of barriers is not only based on organization, legislation, education, but essentially in the field of ideology, politics and society.

Keywords: people with disabilities; social awareness; labor. 